\title{
Correlation of Disgust and Contempt Expressions with Conjugal Dissatisfaction
}

\section{Rui Mateus Joaquim ${ }^{*}$, Tariane Franciele Bastos Pereira' ${ }^{2}$, Laiza de Oliveira Vilela1,2, Tayná Maiara Pilla Rodrigues ${ }^{1}$, Angela Maria da Silva Muniz Brandino ${ }^{3}$, Sandro Caramaschi ${ }^{2}$}

\author{
${ }^{1}$ Faculty of Human Sciences, Federal University of Grande Dourados-UFGD, Dourados, Mato Grosso do Sul, Brazil \\ ${ }^{2}$ Postgraduate Program in Developmental and Learning Psychology, São Paulo State University-UNESP/Bauru, \\ São Paulo, Brazil \\ ${ }^{3}$ Faculdade Anhanguera Educacional de Bauru Bauru, São Paulo, Brazil \\ Email: ${ }^{*}$ ruimateus@hotmail.com
}

How to cite this paper: Joaquim, R.M., Pereira, T.F.B., de Oliveira Vilela, L., Rodrigues, T.M.P., da Silva Muniz Brandino, A.M. and Caramaschi, S. (2018) Correlation of Disgust and Contempt Expressions with Conjugal Dissatisfaction. Journal of Behavioral and Brain Science, 8, 562-573. https://doi.org/10.4236/jbbs.2018.810034

Received: July 18, 2018

Accepted: October 21, 2018

Published: October 24, 2018

Copyright (C) 2018 by authors and Scientific Research Publishing Inc. This work is licensed under the Creative Commons Attribution International License (CC BY 4.0).

http://creativecommons.org/licenses/by/4.0/

\begin{abstract}
Research has shown that dissatisfied couples in the relationship commonly exhibit facial expressions of contempt in interactions. At this point, based on the study of cognition and physiology, researchers were able to predict by longitudinal studies the probability of divorce in a marriage, with accuracy of up to $94 \%$. Our objective was to investigate whether the occurrence of facial expressions of disgust and contempt in married women is associated with marital dissatisfaction. This is an experimental study that correlated, through filmed interviews, the frequency of facial expressions of disgust and disgust (Facial Action Coding System) to the Marital State's Golombok Rust Inventory, in a sample composed of 20 women. Data analysis based on the Spearman Correlation Test showed a positive correlation between facial expressions of disgust and disdain and conjugal dissatisfaction $(\mathrm{rs}=0.2198, \mathrm{p}=0.0280)$, corroborating the data in the literature.
\end{abstract}

\section{Keywords}

Facial Expressions, Disgust, Contempt, Nonverbal Communication, Marital Dissatisfaction

\section{Introduction}

Human communication, a fundamental factor for the understanding of behavior, is associated to the most diverse areas of study, especially linked to non-verbal behavior. Birdwhistell [1] suggests that verbal language would be tied to approximately $35 \%$ of social meaning, while the rest would be defined by multisensory, non-verbalized behaviors. Knapp and Hall [2] describe such 
behavior as arising from non-verbal behavior and classify it mainly in distinct areas: 1) paralanguage (variation of voice characteristics and their interpretations); 2) proxemic (use of space by man); 3) appearance (physical characteristics and clothing; 4) environment (architecture and arrangement of objects in space); 5) kinetics (variety of gestures or expressions and postures).

The study of human facial expressiveness was also initially diffused by Darwin (1872/2016), in his book "The Expressions of Emotions in Man and Animals", and the author emphasized the possibility that there would be a relation between certain emotions and expressions facials. Thus, based on Darwin's [3] observations, human facial expressions would have originated in more primitive evolutionary stages, changing throughout evolution in accordance with the principles of natural selection. His studies were aimed at trying to demonstrate the existence of basic emotions directly linked to the functioning of the autonomic nervous system. In the meantime, the author was able to catalog the expressions of several species and to find consistency in these expressions, defending the hypothesis of the innate characteristic of some facial expressions. The findings of Ekman [4] point to the existence of basic facial expressions. His study confirms Darwin's theory [3] that emotions would be biologically determined and universal, congruent with the emotions presented. Movements of the individual facial muscles were codified by Ekman and Friesen [5] through the Facial Action Coding System (FACS), an instrument that allows measuring all facial expressions or visible facial behaviors, analyzing and describing movements of human face muscles using of a common pattern to systematically categorize the physical expression of emotions. In this regard, recognizing facial expressions of emotions and microexpressions are of great importance for the understanding of interpersonal relationships, intrapersonal management and for the development of emotional intelligence and empathy [5]. The findings on the human face open up a vast horizon of possibilities for behavioral research, expanding the field for exploration and understanding of the emotional meanings of facial behavior.

Damasio [6] reveals that an emotion part of a neural system largely presetted and related to the emotions that send commands to other brain regions and almost all parts of the body. Such commands follow two routes, one of the bloodstream, with commands in the form of chemical molecules that act on receptors on the constituent cells of the tissues of the body and one in neuronal pathways, with commands in the form of electrochemical signals that act on other neurons muscle fibers, or organs. Thus, the organs receiving the command change as a result of these and muscles move as they are commanded.

Disgust, a primary emotion tied to survival, is easily identified in humans from the most diverse cultures and also in some animals. Numerous regulatory reactions, as well as components of the primary emotions, would be an integral part of various combinations of social emotions. Thus, when contempt uses the facial expressions of disgust, which evolves in association with automatic rejection, even in words to describe situations of contempt, it is possible to 
perceive us angry about certain situations [6]. Scorn and disdain are scarcely distinguishable from contempt, and the latter, when mixed with repugnance, would differ little from disgust, an emotion somewhat different in nature, referring to something viscerally repulsive, whether it is really felt or vividly imagined [3]. At this point, considering the difficulties in untying such emotions, the study in question therefore sought to group all the variations presented, in the same category, being denominated as aversive emotions, especially linked to disgust or contempt. It should be noted that Ekman and Ekman [7] also associate contempt as a variation of disgust.

Although the work done by Young, Newcombe, Haan, Small, and Hay [8] indicates specific brain processing for emotion expressions, there is no way to specify a single brain area capable of discriminating all these emotions. Sprengelmeyer [9] suggest that the recognition of different expressions is performed by different neural systems. In this context, neuroimaging studies indicate activation of the anterior insula in the brain when exposed to aversive tastes or visualization of facial expressions of disgust, which is a rather primitive structure [10]. Recently, different studies have shown a strong association between the right hemisphere and emotional processes. In a functional magnetic resonance imaging study, Ishai, Schmidt and Boesiger [11] found that the perception of facial expressions of emotions, although processed in a cortical network distributed by the brain, evokes strong activations in the right hemisphere.

\subsection{Expressions of Emotion and Relationships}

Emotions are seen as components of great importance in the study of behaviors, since they can influence or be influenced by them. Thus, everything that is psychological is simultaneously biological, which gives emotions a highly significant factor [12].

Matsumoto and Hwang [13] conceptualize emotion as an automatic response evoked by virtue of a given stimulus, triggering a physiological response in the body. For these authors, in addition to the elicited internal respondents, the individual also externalizes behaviors that can be observed through physical expressions. It is in this context that Ekman and Friesen [5] point out that the analysis of facial expressions, using the FACS, is able to identify emotions congruent with an individual's emotional responses. In this respect, Ekman [5] suggests that certain emotions are universal and points out that their observation through facial expression does not differ between cultures and may interfere in established relationships and interactions: work, friendships, family and intimate relationships, being of utmost importance in the study of behavior, since this is often the product of these.Some premises detail the importance of the study of emotions, considering the possibility of enumerating the most common specific triggers for a particular emotion, its functioning, causes and involvement in mental disorders, as well as the elaboration of proposals aimed at improving awareness about sensations corporations that embrace them, providing more 
assertive respondents and better readings of others' emotions, being extremely important for relationships and interactions.

In the marriage context, Carrère, Buehlman, Gottman, Coan, and Ruckstuhl [14] predicted, through a longitudinal study of newly married couples, the rate of possible divorces based on facial expressions in physiological precedents such as heart pressure and frequency of heartbeat, sweating, cortisol level, etc. and in the interactions between the spouses. The accuracy of this work resulted in a success rate of $94 \%$. In the results, the authors pointed out that the frequency of divorces was higher in couples who presented a higher incidence of facial expressions of contempt within the marital context.

Another aspect evidenced by the cognitive-behavioral perspective suggests that cognitive responses may affect matrimony as positive and negative experiences gradually accumulate regarding the other's behavior, generating the assessment and consequent satisfaction or dissatisfaction experienced by the spouses [15].

Buehlman and Gottman [16] propose that the verbalization of a given context about the relationship spreads emotions congruent with the couple's perceptions, so the authors synthesize that it would be possible to study conjugal satisfaction by having the spouses report, for example, as is the experience with the other, since the report would result in aspects centered on the current emotion that the individual has about his own marriage. Regardless of the causes that place the divorces, it is a fact that marital separation brings consequences that go beyond the socioeconomic scope.

Studies indicate that divorced individuals have higher rates of psychological disorders, physical illness, suicide, homicide, violence, and disease mortality [17] [18] [19]. In Brazil, a legal update regarding divorces, which took place in July 2010, led to the withdrawal of the requirement of prior judicial separation for more than one year or proven de facto separation for more than two years. As a result of this reduction, in view of the greater ease in the dissolution of marriages, in 2011 there was a growth of $45.6 \%$ in the total number of divorces in the country compared to the previous year, the highest rate since 1984, according to the Brazilian Institute of Geography and Statistics [20].

Within the on-screen field, this research sought to specify the behavior of the human face, since the study of facial expressiveness plays a fundamental role in the communication of emotions, appearing in the recognition of facial expressions as a medium information about the other's emotions [4].

This study is still justified by the importance of deepening the theme about facial expressions, emotions and their influence on marriage, considering that the study by Carrère et al. [14] emphasizes that the recurrence of contempt in evoking memories about the partner in marriage is a factor that may precede divorce. In addition, the findings cited by the author, especially linked to contempt, criticism and blocking or incommunicability, were also observed in other studies that associated them with marital dissatisfaction [21] [22] [23] [24] [25]. 


\subsection{Objective}

From these notes, the present research aimed to correlate the levels of conjugal satisfaction and the frequency of expressions and expressions of facial expression and disgust of women, when talking about their conjugal relationships. The specific objectives were: 1) To identify the levels of marital satisfaction of women in their first relationship; 2) Identify and quantify the occurrence of facial expressions of disgust and contempt evoked by the participants in talking about their marital relationships; 3) Discuss the relationship between disgust, disgust and conjugal dissatisfaction, based on the literature.

\section{Method}

Twenty women, university students, participated in the study in the first marriage relationship, those who were officially married, or in a stable union/living for more than one year with their partner, were allowed to enter the marriage period up to 15 years, considering the most common divorce period in the country (IBGE, 2011). Women who declared use of drugs capable of altering facial expression or having any pathology that interfered with the face were not admitted to the study.

The option for exclusive participation of women was made because although there is no consensus as to the motivations for sexual differences in nonverbal communication, whether biological or social, the research is directed towards considering women to be more expressive in nonverbal terms, better decoders of facial expressions, and more easily describe their emotions and feelings [26] [27] [28] [29].

\subsection{Materials}

Audio and video recording capabilities were used using Sony Cyber Shot 12MP digital camcorder to record the facial expressions presented during the interview script on the marital relationship presented by Gottman and Silver [30]. In order to investigate the level of marital satisfaction, the Golombok Rust Inventory of Marital State (GRIMS) was translated and adapted to Brazilian reality, composed of 28 closed questions, with self-completion, ranging from 0 to 3 points, ordered between totally agree, agree, I totally disagree and disagree. The result obtained at the end ranks the level of marital satisfaction between very good, good, above average, average, poor, bad, severe problems, very severe problems. The reliability analysis, calculated using the Cronbach Alpha coefficient of this scale, showed that the coefficient was 0.9071 [31]. The identification of the facial expressions presented was performed by the researchers prior to the determination of the results of the marital satisfaction assessment scale, so that the evaluations were conducted through a blind study. Thus, expressions of disgust and contempt were identified one by one through the recording. Each identified expression was recorded as a static image for analysis based on the Facial Action Coding System [5]. According to the authors, in the facial expression of disgust and 
disgust are presented distinct muscle groups that come into action for each emotion specifically. Thus, each muscle in the face was classified as an action unit "Action Unities" (AUs). In the facial expressions of disgust, the muscular units are related to the lifter of the upper lip and the wing of the nose (AU 9a), transverse part of the nasal muscle (AU 9b), lifter of the upper lip (AU 10), and angle of the mouth (AU 15). Disregard, in turn, is characterized by the activation of the buccinator muscle (AU 14), being in some cases overlapping with the expression of disgust [5].

\subsection{Procedures}

After submitting and approving the ethics and research committee with human beings (CAAE $\mathrm{n}^{\circ}$ 57983316.7.0000.5493) and the approval was with the consubstantiated opinion $n^{\circ} 1,744,566$. The members had all doubts regarding the study exempted and agreed to their participation by signing the Free and Informed Consent Form. Afterwards, the Golombok Rust Inventory of Marital State self-filling scale was presented and later placed in a sealed envelope for analysis after the interview. At the end of this stage, the study participants were interviewed on the marital relationship based on the script pre-established by Gottman and Silver [30] during which the video recordings were performed.

\subsection{Data Analysis}

The results from the Golombok Rust Inventory of Marital State scale were scored based on the procedures adopted in the instrument adaptation and translation study [31]. The images, obtained from the recording of the interviews, were analyzed through the Facial Action Coding System [5], and the consecutive intervals were measured, each with a duration of 60 seconds, totaling 3000 seconds per filming. For this research the analysis performed considered only the presentation of expressions of disgust or contempt.

\section{Results}

The data collected provided information on the degree of marital satisfaction of each participant, which was correlated to the facial expressions of disgust and contempt presented during the interview. The frequency of expressions and facial microexpressions presented was correlated with the results obtained through the Golombok Rust Inventory of Marital State (GRIMS) [31]. Altogether, 20\% of the interviewed women presented a median score regarding satisfaction level; $60 \%$ of the women presented satisfaction with a score in the above-average categories, good and very good; $20 \%$ of the women had a lower than average score in the categories: poor, severe problems and very serious problems (Table 1). The data presented highlight the occurrence of expressions and facial microexpressions of disgust and disgust obtained through the interviews conducted with an average duration of 14 minutes and 59 minutes, with a minimum of 5 minutes and 33 minutes and a maximum of 23 minutes and 26 
Table 1. Marital satisfaction self-assessment indices with indication of the classification categories according to the score obtained in the Golombok Rust Inventory of Marital State (GRIMS).

\begin{tabular}{ccc}
\hline GRIMS - Score & GRIMS - Classification & Participants (\% - N) \\
\hline$\geq 47$ & Very serious problems & $5 \%(1)$ \\
$42-46$ & Serious problems & $10 \%(2)$ \\
$38-41$ & Bad & $0 \%(0)$ \\
$34-37$ & Poor & $5 \%(1)$ \\
$30-33$ & Medium & $20 \%(4)$ \\
$26-29$ & Above average & $5 \%(1)$ \\
$22-25$ & Good & $20 \%(4)$ \\
$17-21$ & Very good & $35 \%(7)$ \\
$\leq 16$ & Undefined & $0 \%(0)$ \\
\hline
\end{tabular}

minutes. at the end, the occurrence of such expressions by the frequency that occurred per minute. The mean FM (frequency per minute) of these expressions was 0.93 , ranging from 0 to 6.61 . Table 2 shows the results of GRIMS categorization and the frequency per minute of microexpressions and facial expressions of disgust and contempt in each group.

The descriptive statistics presented an arithmetic mean of 27 points in the Golombok Rust Inventory of Marital State and 0.9270 of the frequency of facial microexpressions of disgust or contempt, with a standard deviation of 11.4 and 1.497, respectively. The sample was submitted to the D'Agostino normality test, and a parametric distribution was identified in the results of the Golombok Rust Inventory of Marital State and non-parametric in the expressions and microexpressions of disgust and disgust, thus opting for the use of non-parametric statistics. In the comparison of groups with scores above and below the mean in GRIMS with the Mann Whitney test there was no statistically significant difference in the analysis performed.

When correlating the frequency of facial expressions of disgust and contempt presented with the results obtained in the scale of assessment of conjugal satisfaction through the Spearman Correlation Test, it was observed that women who presented higher rates related to dissatisfaction in the marriage expressed more quantity of expressions and microexpressions of disgust and contempt per minute $(\mathrm{rs}=0.2198, \mathrm{p}=0.0280)$.

\section{Discussion}

The objective of this study was to correlate facial expressions of disgust and contempt of married women and dissatisfaction in the marital relationship. Participants were invited to fill out a marital satisfaction assessment scale and then report the relationship history through the roadmap suggested by Gottman and Silver [30]. 
Table 2. Scoring in the Golombok Rust Inventory of Marital State (GRIMS) and frequency of expressions and microexpressions disgust/contempt per minute.

\begin{tabular}{|c|c|c|c|}
\hline GRIMS & Participants & $\begin{array}{c}\text { Frequency } \\
\text { Disgust/Contempt }\end{array}$ & Group average \\
\hline \multirow{5}{*}{ Very good } & P5 & 1.08 & \multirow{5}{*}{0.56} \\
\hline & P7 & 0.84 & \\
\hline & P8 & 0.56 & \\
\hline & P14 & 0.20 & \\
\hline & P17 & 0.10 & \\
\hline \multirow{4}{*}{ Good } & P3 & 2.18 & \multirow{4}{*}{0.82} \\
\hline & P10 & 0.50 & \\
\hline & P11 & 0.39 & \\
\hline & P13 & 0.22 & \\
\hline \multirow[t]{2}{*}{ Above average } & P16 & 0.10 & 0.10 \\
\hline & P2 & 2.19 & \multirow{4}{*}{0.71} \\
\hline \multirow{3}{*}{ Medium } & P9 & 0.54 & \\
\hline & P15 & 0.11 & \\
\hline & $\mathrm{P} 20$ & 0 & \\
\hline Poor & $\mathrm{P} 4$ & 1.56 & 1.56 \\
\hline $\mathrm{Bad}$ & 0 & 0 & 0 \\
\hline \multirow[b]{2}{*}{ Serious problems } & P1 & 6.61 & \multirow[b]{2}{*}{3.48} \\
\hline & P12 & 036 & \\
\hline Very serious problems & P6 & 1.00 & 1.00 \\
\hline
\end{tabular}

According to the literature, marital separation can occur through high doses of criticism, contempt, and defensive and obstructive behavior. The identification of destructive emotions in the mainstream study takes into account the occurrence of contempt, according to Gottman and Silver [30], and even has an important influence on the divorce rate. Pereira [32] emphasizes that a marriage consists basically of a collaborative game, where the relationships would be based on trust and reciprocity, with the premise that as one spouse exposes his weaknesses and secrets to the other, he trusts that he will make good use of this information and it will not harm you. However, when negative emotions permeate this relationship it becomes quite difficult to maintain this system, given that the product of these emotions would be related to harmful habits.

On the other hand, the researchers also propose methods of intervention that lead to improvement in marital satisfaction and relationships. In this way, the identification of these negative emotions can serve as a basis for couples' self-awareness and a new configuration of their behavior in the relationship. Gottman and Gottman [33] suggest, for example, that some, albeit seemingly simple, measures can drastically change marital quality. This set of actions was 
termed by the authors as "The Sound Relationship House Theory" and includes mainly the construction of an affective reserve through mental maps, which would be memories about the partner, reasons for which they fell in love, interest and affective and sexual knowledge on the other; the maintenance of a system of respect, affection and admiration, appreciating the qualities and achievements of the partner; successful attempts at connection, permeated by reciprocity in attention, interest, desire to talk, good humor, empathy, sexual warmth, support and assistance, etc., as well as identification and avoidance of negative or non-reciprocal responses.

Mussumeci and Ponciano [34], in a study with couples, where stress, coping and emotional experiences were evaluated, describe that marital satisfaction is not linked to the experience of negative experiences in themselves, but in the coping way of each couple. Thus, satisfied couples in the relationship, in reporting their experiences, cite them with positive emotions, and report difficult moments that have passed with good humor and mutual support, corroborating that difficult situations can be accompanied by positive emotions.

\section{Conclusions}

Studies have shown that emotions can, to a large extent, influence behaviors. Based on this knowledge, the present work sought to investigate the relationship between facial expressions of emotions and behavior, especially linked to the marital context, making the association between facial expressions of disgust and disgust and conjugal dissatisfaction. The data presented suggest that, in consonance with the literature, there is a significant association between emotions of disgust and disgust and conjugal dissatisfaction. However, it is a fact that this scenario needs to be detailed, since only the study of nonverbal communication of an individual does not determine underlying behaviors, and other aspects that may interfere with these results must be evaluated. Another point emphasized by the research denotes the need for expansion to the study of other negative emotions.

In addition, it is important to note that the occurrence of disgust or contempt does not characterize degree of dissatisfaction, since even satisfied women in the relationship had such expressions of emotions, however, the findings of this work denote a significantly higher frequency of expressions and facial microexpressions of disgust and contempt in women with lower rates of marital satisfaction. This study investigated only the variables presented in the dissatisfaction and facial expressions, in a future perspective, if the method could be applied in a more consistent sample, as well as its extension to other groups, such as couples with violent relationships, for example, where they could motivate to maintain abusive and aggressive relationships that are under study. Another point refers to the need to extend the measurement of other variables that were not used, such as the analysis of verbal discourse.

Still treated as a "background", non-verbal behavior is a very important factor 
to be considered and must be studied systematically. This was the proposal exposed by the work in question, which is homogenized to the findings on conjugal dissatisfaction and facial expressiveness.

\section{Conflicts of Interest}

The authors declare no conflicts of interest regarding the publication of this paper.

\section{References}

[1] Birdwhistell, R.L. (1970) Kinesics and Context: Essays on Body Motion Communication. University of Pennsylvania Press, Filadélfia.

[2] Knapp, M.L. and Hall, J.A. (1999) Comunicação não-verbal na interação humana. JNS Editora Ltda, São Paulo.

[3] Darwin, C. (1872/2016) A Expressão das emoções no homem e nos animais. Cia das Letras, São Paulo.

[4] Ekman, P. (2015) Emotion in the Human Face. 2nd Edition, Malor Books, New York, NY.

[5] Ekman, P. and Friesen, W. (1978) Facial Action Coding System: A Technique for the Measurement of Facial Movement. Consulting Psychologists Press, Palo Alto.

[6] Damásio, A. (2000) O mistério da consciência. Companhia das Letras, São Paulo.

[7] Ekman, P. and Ekman, E. (2017) The Ekman's Atlas of Emotions. http://atlasofemotions.org

[8] Young, A.W., Newcombe, F., de Haan, E.H.F., Small, M. and Hay, D.C. (1993) Face Perception after Brain Injury: Selective Impairments Affecting Identity and Expression. Brain, 116, 941-959. https://doi.org/10.1093/brain/116.4.941

[9] Sprengelmeyer, R., Young, A.W., Calder, A.J., Karnat, A., Lange, H., Homberg, V., Perrett, D.I. and Rowland, D. (1996) Perception of Faces and Emotions: Loss of Disgust in Huntington's Disease. Brain, 119, 1647-1665. https://doi.org/10.1093/brain/119.5.1647

[10] Phillips, M.L., Young, A.W., Senior, C., Brammer, M., Andrew, C., Calder, A.J., Bullmore, E.T., Perrett, D.I., Rowland, D., Williams, S.C.R., Gray, J.A. and David, A.S. (1997) A Specific Neural Substrate for Perceiving Facial Expressions of Disgust. Nature, 389, 495-498. https://doi.org/10.1038/39051

[11] Ishai, A., Schmidt, C.F. and Boesiger, P. (2005) Face Perception Is Mediated by a Distributed Cortical Network. Brain Research Bulletin, 67, 87-93. https://doi.org/10.1016/j.brainresbull.2005.05.027

[12] Mayers, D.G. (2012) Psicologia. 9th Edition, LTC, Rio de Janeiro.

[13] Matsumoto, D. and Hwang, H.S. (2011) Evidence for Training the Ability to Read Microexpressions of Emotion. Motivation and Emotion, 35, 181-191. https://doi.org/10.1007/s11031-011-9212-2

[14] Carrère, S., Buehlman, K.T., Gottman, J.M., Coan, J.A. and Ruckstuhl, L. (2000) Predicting Marital Stability and Divorce in Newlywed Couples . Journal of Family Psychology, 14, 42-58. https://doi.org/10.1037/0893-3200.14.1.42

[15] Gottman, J.M. (1993) A Theory of Marital Dissolution and Stability. Journal of Family Psychology, 7, 57-75. https://doi.org/10.1037/0893-3200.7.1.57

[16] Buehlman, K., Gottman, J.M. and Katz, L. (1992) How a Couple Views Their Past Predicts Their Future: Predicting Divorce from an Oral History Interview. Journal 
of Family Psychology, 5, 295-318. https://doi.org/10.1037/0893-3200.5.3-4.295

[17] Berkman, L.F. and Breslow, L. (1983) Health and the Ways of Living: The Alameda County Study. Oxford University Press, New York.

[18] Frisby, B.N., Booth-Butterfield, M., Dillow, M.R., Martin, M.M. and Weber, K.D. (2012) Face and Resilience in Divorce: The Impact on Emotions, Stress, and Post-Divorce Relationships. Journal of Social and Personal Relationships, 29, 715-735. https://doi.org/10.1177/0265407512443452

[19] Schrodt, P., Witt, P.L. and Shimkowski, J.R. (2014) A Meta-Analytical Review of the Demand/Withdraw Pattern of Interaction and Its Associations with Individual, Relational, and Communicative Outcomes. Communication Monographs, 81, 28-58. https://doi.org/10.1080/03637751.2013.813632

[20] Instituto Brasileiro de Geografia e Estatística (2011) Análise dos resultados. http://downloads.ibge.gov.br/downloads_estatisticas.htm

[21] Horan, S.M., Guinn, T.D. and Banghart, S. (2015) Understanding Relationships among the Dark Triad Personality Profile and Romantic Partners' Conflict Communication. Communication Quarterly, 63, 156-170. https://doi.org/10.1080/01463373.2015.1012220

[22] Babcock, J.C., Gottman, J.M., Ryan, K.D. and Gottman, J.S. (2013) A Component Analysis of a Brief Psycho Educational Couples' Workshop: One Year Follow up Results. Journal of Family Therapy, 35, 252-280. https://doi.org/10.1111/1467-6427.12017

[23] Gottman, J.M., Driver, J. and Tabares, A. (2015) Repair during Marital Conflict in Newlyweds: How Couples Move from Attack-Defend to Collaboration. Journal of Family Psychotherapy, 26, 85-108. https://doi.org/10.1080/08975353.2015.1038962

[24] Shapiro, A.F., Gottman, J.M. and Fink, B.C. (2015) Short-Term Change in Couples' Conflict Following a Transition to Parenthood Intervention. Couple and Family Psychology: Research and Practice, 4, 239-251. https://doi.org/10.1037/cfp0000051

[25] Hooper, A., Spann, C., McCray, T. and Kimberly, C. (2017) Understanding Potential Demographic Differences with John Gottman's Four Horsemen and Emotional Flooding. The Family Journal, 25, 224-229. https://doi.org/10.1177/1066480717710650

[26] Hall, J.A. (1978) Gender Effects in Decoding Nonverbal Cues. Psychological Bulletin, 85, 845-857. https://doi.org/10.1037/0033-2909.85.4.845

[27] McClure, E.B. (2000) A Meta-Analytic Review of Sex Differences in Facial Expression Processing and Their Development in Infants, Children, and Adolescents. Psychological Bulletin, 126, 424-453. https://doi.org/10.1037/0033-2909.126.3.424

[28] Reber, R. and Flammer, A. (2002) The Development of Gender Differences in Affective Expression and in the Relationship between Mood and Achievement-Related Self-Judgements. European Journal of Psychology of Education, 17, 377-392. https://doi.org/10.1007/BF03173592

[29] Fischer, A. and LaFrance, M. (2015) What Drives the Smile and the Tear: Why Women Are More Emotionally Expressive than Men. Emotion Review, 7, 22-29. https://doi.org/10.1177/1754073914544406

[30] Gottman, J.M. and Silver, N. (2016) The Seven Principles for Making Marriage Work. Random House, New York.

[31] Falcke, D. (2003) Águas passadas não movem moinhos? As experiências na família de origem como preditoras da qualidade do relacionamento conjugal. Tese doutorado, Pontifícia Universidade Católica do Rio Grande do Sul, Porto Alegre. 
[32] Pereira, R. (2015) Por que não se separam: A perda da confiança no relacionamento conjugal. Pensando Famílias, 19, 3-20.

[33] Gottman, J. and Gottman, J. (2017) The Natural Principles of Love. Journal of Family Theory and Review, 9, 7-26. https://doi.org/10.1111/jftr.12182

[34] Mussumeci, A.A. and Ponciano, E.L.T. (2017) Estresse, coping e experiências emocionais: Uma análise das respostas de enfrentamento do casal. Pensando familias, 21, 33-49. 